\title{
O PAPEL DA GESTÃO NA FORMAÇÃO INICIAL DE PROFESSORES COM VISTAS À EDUCAÇÃO INCLUSIVA
}

\author{
Charline Fillipin Machado \\ Universidade Federal de Santa Maria, Brasil. \\ Fabiane Adela Tonetto Costas \\ Universidade Federal de Santa Maria, Brasil.
}

\begin{abstract}
Resumo
Considerando o atual sistema de educação inclusiva cabe ao ensino regular fornecer a educação básica em todas as esferas. Diante disso, evidencia-se a importância do investimento na formação docente, pois é na academia que se encontra o primeiro e um dos mais importantes ambientes de instrução e troca de saberes, no qual se formam os profissionais que atuarão no amanhã. Esta pesquisa pretendeu verificar quais alternativas organizativas e estruturais a gestão da UFSM está buscando ou deve buscar para colaborar na formação inicial de professores qualificados para atuar na escola inclusiva. Em síntese, a qualidade da formação de professores para trabalhar na educação inclusiva está em construção, problemas ainda são encontrados, principalmente em relação à própria formação dos formadores.

Palavras-chave: educação inclusiva, formação inicial de professores, gestão no ensino superior, políticas públicas.
\end{abstract}

\section{MANAGEMENT'S ROLE ON INITIAL FORMATION OF TEACHERS AIMING TO INCLUSIVE EDUCATION}

\begin{abstract}
Considering the current inclusive education system, it is up to the regular teaching provide the basic education at all scopes. Facing that, the importance of investing into the teacher's formation is verified, for it is inside the academy that the first and one of the most important instruction and knowledge exchanging environments is found; there the professionals which will act tomorrow are formed. This research intended to verify which organizational and structural alternatives UFSM's management is or should be looking for in order to collaborate to a initial formation of teachers with qualification to act inside the inclusive school. In summary, the quality of training of teachers to work inside inclusive education is being built, with troubles being found, especially in relation to the teachers' formation.

Key-words: inclusive education, teacher's initial formation, superior teaching's management, public politics.
\end{abstract}




\section{Introdução}

A educação especial caracteriza-se como modalidade de ensino transversal, perpassando por todos os níveis, etapas e modalidades, não sendo mais um sistema paralelo como permaneceu por um longo período na história educacional de nosso país. Nesse sentido, é papel do professor de Educação Especial complementar ou suplementar o ensino dos sujeitos com necessidades educacionais especiais, cabendo ao ensino regular fornecer a educação básica nas diferentes esferas para a formação desses sujeitos.

Em face disso, um dos principais fatores que influencia diretamente nesta ação é a formação de professores. Evidencia-se como de fundamental importância o investimento na formação docente, pois é na academia que se encontra o primeiro e mais importante ambiente de instrução e troca de saberes, no qual se formam os profissionais que atuarão no amanhã. Além do mais, é na formação inicial de professores que se pode compreender o contexto global da educação inclusiva, reconhecendo, assim, a atual política educacional brasileira. Desse modo, é fundamental uma formação condizente com os aspectos que permeiam essa proposição.

Articulando-se políticas públicas educacionais e gestão universitária, destaca-se que, entre os objetivos e as metas do Plano Nacional de Educação - PNE, encontrava-se "incluir nos currículos de formação de professores, nos níveis, médio e superior, conteúdos e disciplinas específicas para a capacitação ao atendimento dos alunos especiais". Cabe ressaltar que esse documento teve vigência até o ano de 2010; sendo assim, suas metas deveriam ser alcançadas neste período.

No entanto, por meio de pesquisa anterior ${ }^{1}$, constatou-se que, entre dezessete cursos de licenciatura da Universidade Federal de Santa Maria (UFSM), seis ainda não possuíam disciplina de educação especial como obrigatória em sua grade curricular. Logo, percebe-se que, na instituição, a meta relacionada à obrigatoriedade da capacitação aos futuros professores, para atender alunos especiais, não foi totalmente alcançada ao final de sua vigência.

Além dessas informações, através da pesquisa supracitada, outras premissas referentes aos problemas interligados à formação e à inclusão foram mencionadas pelos acadêmicos que participaram do estudo. A partir destas constatações, novos aspectos evidenciam-se, entre eles, destaca-se a eficácia das disciplinas sobre Educação Especial e educação inclusiva, como também a organização da instituição no que diz respeito à contemplação de ações em torno desta faceta. Assim, considerou-se necessário questionar se as disciplinas de Educação Especial oferecidas aos cursos de licenciatura da UFSM estão contribuindo para o incremento formativo dos futuros professores sobre a educação inclusiva e as necessidades educacionais.

Logo, torna-se necessária a relação da gestão dos cursos, assim como da instituição como um todo, com tais propósitos, pois lhes cabe a responsabilidade de tecer o fio condutor entre a realidade e as proposições que qualificam as ações na formação docente. Sendo assim, neste estudo, questionou-se quais alternativas organizativas e estruturais a gestão da instituição está buscando ou deve buscar para colaborar na formação de professores qualificados para atuar na escola inclusiva? Imbricado a esse

\footnotetext{
1 Trabalho de conclusão de curso apresentado como requisito para o grau de Educadora Especial pela UFSM. 
questionamento, outras indagações põem-se, como: que papel teria os gestores quando se pensa na "construção" de educadores comprometidos com princípios sociais - atuais inclusivos? Seria a formação inicial responsável por garantir qualidade e efetivação dos princípios da educação inclusiva? Além disso, apenas disciplinas isoladas são suficientes para tal propósito?

Tais questionamentos guiaram a pesquisa desenvolvida no curso de Especialização em Gestão Educacional a qual buscou propor uma reflexão em torno das relações que a gestão dos cursos - e da instituição - estabelece com as políticas públicas direcionadas à inclusão, tendo como ponto norteador a formação inicial de qualidade aos futuros docentes. Tal ação faz-se necessária à medida que deveria refletir nos princípios de uma Educação Básica com igualdade de direitos e, sobretudo, de qualidade.

Deste modo, o estudo apresentado aqui parte das discussões realizadas na pesquisa supramencionada. Esta teve como aspectos metodológicos a abordagem qualitativa, pois ela "trabalha com o universo dos significados, dos motivos, das aspirações, das crenças, dos valores e das atitudes" (Minayo, 2011, p. 21). Sendo assim, por meio de uma investigação qualitativa, buscou-se compreender os significados, as intencionalidades e as atitudes envolvidas no que se refere ao papel da gestão na formação de professores que considere as atuais políticas educacionais de educação inclusiva.

Teve-se como foco de estudo a gestão dos cursos de licenciatura da UFSM, especificamente as coordenações, no que tange a que componentes formativos os cursos oferecem para capacitação de profissionais diante dos princípios da educação inclusiva. Logo, esta pesquisa, por ser qualitativa, voltou-se aos significados que os gestores envolvidos na formação de professores agregam às inquietações levantadas.

Para o desenvolvimento deste estudo, foi realizada a investigação direta com os coordenadores dos cursos de licenciatura, tendo como critério de amostra todos os coordenadores dos cursos de licenciatura da UFSM ${ }^{2}$. Os cursos que compõem a pesquisa totalizam-se em dezenove e estão distribuídos em cinco unidades universitárias. No entanto, alguns desses cursos possuem uma mesma coordenação, assim totalizaramse em quinze coordenadores convidados a participar da pesquisa. Destes, apenas oito participaram. Como forma de manter sigilo de identidade, no decorrer do texto, serão designadas, aos coordenadores, letras $(A$ até $H)$, que foram classificadas em ordem alfabética aleatoriamente.

A coleta de dados teve como principal instrumento o uso de questionário, além da pesquisa documental que, no contexto desta pesquisa, fez-se indispensável. Entre os documentos estudados encontram-se as leis, políticas, decretos, regimentos em âmbito nacional e também internos da instituição ${ }^{3}$, a fim de reconhecer as informações referentes à educação inclusiva que dizem respeito à formação de professores e, assim, a relação com a gestão da UFSM em torno do propósito.

Quanto à coleta de dados por meio de questionário, Gil (1999) destaca que é possível o conhecimento de opiniões, crenças, sentimentos, interesses, expectativas, situações vivenciadas. Além do mais, acredita-se que, através deste instrumento, os

\footnotetext{
${ }^{2}$ Trabalhou-se com todos os cursos de licenciatura exceto o curso de Educação Especial, pois a discussão em torno desta modalidade na educação inclusiva se dá de formas diferenciadas das demais licenciaturas.

${ }^{3}$ Projeto político pedagógico, programas das disciplinas, entre outros.

Regae: Rev. Gest. Aval. Educ.

$3 \quad$ Jan./jun. 2013

p. 73-92
} 
sujeitos da pesquisa sentem-se mais à vontade para expressar-se inicialmente, contribuindo também para que a opinião pessoal do pesquisador não influencie os sujeitos (Gil, 1999).

Por fim, para análise dos dados, optou-se pelo procedimento de Análise de Conteúdo. Assim a análise dos dados seguiu três pólos cronológicos descritos por Bardin (1977): a pré-análise, a exploração do material e o tratamento dos resultados, a inferência e a interpretação. Na pré-análise, buscou-se operacionalizar e sintetizar as ideias iniciais, conduzindo esquemas para facilitar as operações sucessivas. Na fase de exploração do material, houve a análise com a administração sistemática das decisões tomadas anteriormente. Logo, no tratamento dos resultados obtidos e interpretação, os resultados foram tratados de acordo com os objetivos e discutidos a fim de se tornarem significativos e válidos.

\section{Educação especial com vistas à educação inclusiva: construção histórica e políticas públicas}

Para chegar à atual proposta de educação inclusiva, o sistema de ensino brasileiro, caminhando a passos lentos, passou por diversas etapas, vivendo diferentes políticas, leis, normativas, resoluções e diretrizes. Após a educação dos sujeitos com necessidades especiais perpassar por diversas discussões, é com a Política Nacional de Educação Especial, na Perspectiva da Educação Inclusiva de 2008 (Brasil, 2008), que se garante, com maior ênfase, o direito de uma educação de todos os sujeitos em escola regular. Esta política apresenta como objetivo "assegurar a inclusão escolar de alunos com deficiência, transtornos globais do desenvolvimento e altas habilidades/superdotação" (Brasil, 2008, p. 14).

A histórica da Educação Especial evidencia o longo percurso na organização de ações para a educação do sujeito com necessidades educacionais especiais até chegar à atual proposta de Educação Inclusiva. Assim, o momento atual recupera a história da educação como busca de esforços para a implementação efetiva e com qualidade de uma educação inclusiva, através de propostas pedagógicas que tornem possível receber todo aluno, seja qual for sua especificidade. Nessa perspectiva, cabe à escola não apenas receber o aluno com necessidades educacionais especiais, mas também proporcionar-lhe um ambiente, no qual sejam possíveis as trocas para o desenvolvimento do aprendizado em todos os níveis de saberes propostos pela instituição.

No entanto, o fato de existir uma política que oriente a organização para a implementação da educação inclusiva nem sempre se encontra a sua concretização no âmbito escolar. Acredita-se que não é com a obrigatoriedade que será possível o alcance a uma pedagogia inclusiva positiva e efetiva. Refletindo sobre estes aspectos, Beyer (2006, p. 81) afirma que

é pelo convencimento gradual, por meio da exposição convincente de todos os aspectos que constituem as principais bases (filosóficas, psicológicas, sociais e pedagógicas) do projeto inclusivo, que os professores e educadores em geral poderão se tornar peças estratégicas deste jogo fascinante que se chama educação inclusiva. 
Ainda que esse convencimento e a exposição clara e massiva acerca dos pressupostos da educação inclusiva não sejam realidade, existe, hoje, um movimento mundial pela inclusão, que se estabelece a partir de ações políticas, culturais, sociais, além de pedagógicas, a fim de garantir o direito de todos os alunos estarem juntos aprendendo e compartilhando de uma educação de qualidade, sem nenhum tipo de discriminação (Brasil, 2008).

Ao longo de 90 anos, a educação especial foi evoluindo em termos de conceitos e propostas institucionais. A caracterização da educação inclusiva traz, como princípio, a heterogeneidade na classe escolar, promovendo interações entre crianças com necessidades e potencialidades específicas. No entanto, apenas a interação não é suficiente, é necessário "uma pedagogia que se dilate frente às diferenças do alunado" (Beyer, 2006, p. 73), propondo, dessa forma, aprendizagens recíprocas que favoreça o desenvolvimento de todos.

\section{Formação inicial de professores com vistas à educação inclusiva}

Atualmente evidencia-se diversas mudanças no sistema educacional decorrente dos avanços científicos, tecnológicos, entre outros que trazem consigo novas exigências aos professores, assim repercutindo na sua formação. Essas exigências trazem como base principalmente a relação entre escola e sociedade, e, acima de tudo, a implementação de um projeto de educação escolar que se posicione em relação às mudanças e obrigações sociais, e à organização do sistema nacional de ensino em torno dos temas recorrentes da educação (Libâneo, 2006). Considerando essas exigências, para o aprimoramento da educação para todos, é necessário o investimento na formação de professores, pois

o professorado, diante das novas realidades e da complexidade de saberes envolvidos presentemente na sua formação profissional, precisaria de formação teórica mais aprofundada, capacidade operativa nas exigências da profissão, propósitos éticos para lidar com a diversidade cultural e a diferença. (Libâneo, 2006, p. 77)

Portanto, pensar em um sistema de formação de professores remete-se à reavaliação dos objetivos, conteúdos, métodos, formas de organização do ensino e princípios educacionais diante da realidade em transformação. Vindo ao encontro da reflexão tomada aqui, a formação de professores hoje deve considerar a nova realidade da educação inclusiva, apresentando subsídios, através dos conteúdos, métodos, conceitos e princípios, para que os futuros professores ofereçam um ensino de qualidade aos educandos.

Acredita-se que todos os professores devam ter formação para receber e trabalhar com a diversidade, proporcionando aos educandos um ensino de qualidade que respeite suas necessidades. Neste contexto pode-se afirmar que a "formação geral de qualidade dos alunos depende de formação de qualidade dos professores". (Libâneo, 2006, p. 83).

Logo, pode-se afirmar que

há estreita relação entre a qualidade de ensino na universidade e o trabalho docente realizado em sala de aula. A premissa é muito simples: o núcleo de uma instituição universitária é a qualidade e eficácia dos processos de ensino e aprendizagem que, alimentados pela pesquisa, 
promovem melhores resultados de aprendizagem dos alunos. Ou seja, a universidade existe para que os alunos aprendam conceitos, teorias; desenvolvam capacidade e habilidades; formem atitudes e valores e se realizem como profissionais-cidadãos. É para isso que são formulados os projetos pedagógicos, os planos de ensino, os currículos, os processos de avaliação. (Libâneo, 2005, p. 1)

Além do mais, o que se torna preocupante no âmbito da formação docente e principalmente, da formação docente para a diversidade, é o fato de, muitas vezes, os cursos passarem uma visão simplista da educação especial, assim como da educação inclusiva, que não colabora para o reconhecimento verdadeiro de tais áreas, o que faz continuar o reforço dos mitos que podem interferir em um trabalho docente de qualidade para os alunos.

Corroborando com o exposto, Tardif (2002), ao explanar sobre os saberes profissionais dos professores, destaca o fato dos alunos passarem pelos cursos de formação de professores sem modificar suas crenças anteriores sobre o ensino. "E, quando começam a trabalhar como professores, são principalmente essas crenças que eles reativam para solucionar seus problemas profissionais" (p. 261).

Desse modo, a falta de entendimento e de conhecimento a respeito da inclusão escolar e de seu alunado pode acarretar sérios problemas, até mesmo a exclusão de alguns alunos. No entanto, espera-se que, nesse espaço de formação, seja proporcionado aos futuros professores a quebra das crenças que trazem uma visão errônea sobre os aspectos que permeiam a educação inclusiva e seu alunado. Isso contribui com a busca de subsídios que melhor resolvam os prováveis problemas que encontrarão na prática.

Nesta linha de pensamento, entende-se que a formação inicial de professores deva ser fator de problematização ao rever as ações que contribuem para uma pedagogia inclusiva, pois, para se prover uma educação que atenda a todos os alunos sem classificações, é necessária a consolidação de uma pedagogia capaz de suprir as necessidades das crianças, considerando as especificidades de cada uma. Para tanto, é fundamental a reformulação do currículo de formação de professores de pedagogia e licenciaturas para contemplar a heterogeneidade escolar (Beyer, 2006).

As instituições de ensino superior são as grandes responsáveis pelo contingente de profissionais atuantes no sistema regular de ensino. Nessa perspectiva, é essencial que a universidade, como agência de formação de profissionais, assuma, juntamente com o sistema de ensino, iniciativas que ofereçam suporte a tais profissionais de forma a contribuir no processo de inclusão (Jesus, 2006).

Retomando Beyer (2006), quando assevera que o professor só se tornará parte do processo de inclusão a partir de seu convencimento, acredita-se que é, na formação inicial de professores, o momento propício para se iniciar esse processo de "convencimento", através do conhecimento das principais bases do projeto inclusivo. Quando o professor sentir-se como protagonista desta ação, envolvido e sensibilizado com o desenvolvimento dos seus educandos, é que poderão surgir efeitos inclusivos frente à escola.

Tal necessidade é subsidiada por políticas públicas, as quais buscam assegurar aos cursos de formação de professores princípios de conhecimento para a atuação no 
sistema de ensino inclusivo. Entre estas se encontra a resolução CNE/CP n. 1/2002, que estabelece as diretrizes curriculares nacionais para a formação de professores da educação básica. Em uma perspectiva de educação inclusiva, o documento define que as instituições de ensino superior devem prever em sua organização curricular formação docente voltada para atender à diversidade e que contemple conhecimentos sobre as especificidades dos alunos com necessidades educacionais especiais.

Outra política pública que sustenta a necessidade de formação docente é o Plano Nacional de Educação - PNE (Brasil, 2001) o qual traz como objetivo: "Incluir nos currículos de formação de professores, nos níveis médio e superior, conteúdos e disciplinas específicas para a capacitação ao atendimento dos alunos especiais" (p. 68). O documento traça uma discussão sobre a necessidade de preparação do corpo docente e do corpo técnico e administrativo das escolas, destacando que todos os professores deveriam ter conhecimento da educação de alunos especiais (Brasil, 2001, p. 62-63).

Logo, ao levantar a necessidade de aprimoramento nas instituições de Ensino Superior no que se refere à formação para a educação inclusiva, destaca-se, além das leis e políticas que afirmam a necessidade de formação para a educação inclusiva, a função clássica da universidade, pois ela "transmite o saber historicamente acumulado, é uma instância questionadora desse saber, é criadora de novos saberes. Ela também precisa saber responder à realidade histórica, social, política, cultural, científica" (Libâneo, 2005, p. 8).

\section{Gestão educacional: da formação docente a educação básica}

Ao refletir sobre os princípios da qualidade e da melhoria da educação, não há como negar a influência e significância do papel da gestão educacional, especialmente quando se refere às políticas públicas educacionais e as suas concretizações em sentidos mais amplos e não, necessariamente, diretamente ligados. Nesse contexto, pensar a formação de professores comprometida e consciente com as atuais políticas educacionais de inclusão remete aos objetivos da gestão educacional no campo do Ensino Superior, principalmente em torno da organização, mobilização, articulação e participação de todas as instâncias.

Desde a LDB já são garantidos os princípios de gestão democrática, não apenas na educação básica, mas também no ensino superior. Isso se confirma no art. 56. da LDB: "As instituições públicas de educação superior obedecerão ao princípio da gestão democrática, assegurada a existência de órgãos colegiados deliberativos, de que participarão os segmentos da comunidade institucional, local e regional".

A partir disso, faz-se necessário compreender o conceito de gestão educacional. Assim, Heloísa Lück ${ }^{4}$ conceitua:

Gestão educacional corresponde ao processo de gerir a dinâmica do sistema de ensino como um todo e de cooperação das escolas em específico, afinado com as diretrizes e políticas educacionais públicas para implementação das políticas educacionais e projetos pedagógicos das escolas, compromissado com os princípios da democracia e com métodos que organizem e criem condições para um ambiente educacional

\footnotetext{
${ }^{4}$ Neste trabalho, quando se refere às escolas, compreende-se também as instituições de ensino superior. \begin{tabular}{|l|l|l|l|l|l|}
\hline Regae: Rev. Gest. Aval. Educ. & Santa Maria & v. 2 & n. 3 & Jan./jun. 2013 & p. 73-92
\end{tabular}
} 
autônomo [...] de participação e comprometimento [...], autocontrole [...] e transparência. (Lück, 2006, p.35).

Traçando o rumo da reflexão, torna-se oportuno esclarecer que, quando se fala em gestão educacional não se remete apenas a escola ou instituição como lócus de ensino, mas sim a todas as dimensões e segmentos que compõem o sistema de ensino, desde o âmbito governamental, político, secretarias de educação e órgãos regionais. De acordo com Lück (2006), o conceito de gestão "não se refere a este ou aquele segmento, mas ao sistema de ensino como um todo, tanto horizontal quanto verticalmente, e, portanto, não se constitui em uma função circunscrita a quem detém o cargo/função maior de uma unidade de trabalho" (p.36-37).

Sem negar as dificuldades para se concretizar uma gestão democrática - portanto, participativa e colaborativa - no Ensino Superior, em muitos momentos quando se refere à instituição de ensino superior é comum o termo administração em vez de gestão. Muitas vezes, é apenas a administração do ensino que prevalece.

Por muito tempo, foi usado apenas o termo administração do ensino, sendo necessária, a partir dos princípios educacionais, a mudança para gestão educacional. Em vista disso, Lück (2006) ao discutir sobre a mudança paradigmática de administração para gestão, ressalta que se deve ter claro que não se refere apenas a uma substituição terminológica:

Trata-se, assim, da proposição de um novo entendimento de organização educacional e de seus processos e, para, além disso, das relações da educação com a sociedade e das pessoas dentro do sistema de ensino e da escola. Cabe ressaltar, ainda, que a gestão não se propõe a depreciar ou invalidar a importância da administração, mas, sim, a superar as limitações de enfoque fragmentado, simplificado e reduzido. (Lück, 2006, p. 53).

Neste enfoque, a administração passa a ser considerada uma dimensão da gestão. Sendo assim, hoje, as instituições de ensino devem ser organizadas e mantidas através da gestão educacional, uma gestão participativa e democrática que

abrange a articulação dinâmica do conjunto de atuações como prática social que ocorre em uma unidade ou conjunto de unidades de trabalho, que passa a ser o enfoque orientador da ação organizadora e orientadora do ensino, tanto em âmbito macro (sistema) como micro (escola) e na interação de ambos os âmbitos (Lück, 2006, p. 112).

Nessa configuração, a gestão educacional não contempla somente a gestão da instituição de ensino (micro), mas sim abrange a totalidade da educação, ou seja, todo o sistema de ensino (macro). Para as questões levantadas aqui, cabe enfatizar que, na gestão de âmbito macro, pode-se destacar as políticas públicas educacionais, assim como as ações e os programas do governo, os quais se entrelaçam às ações educacionais, principalmente quando diz respeito à inclusão de alunos com necessidades especiais e à formação dos professores da sala regular.

Desse modo, são evidentes as relações e os encadeamentos entre a gestão macro e micro, sendo que, para efetivas melhorias no sistema de ensino e de qualidade 
educacional, um âmbito reflete no outro. Da mesma forma, pode-se afirmar que duas diferentes instâncias de âmbito micro podem se influenciar significativamente, como é o caso das instituições de ensino superior e das de educação básica. Considerando a forte ligação entre o nível de ensino que forma os profissionais que irão atuar, gerir, concretizar a Educação Básica, não é difícil entender tal relação.

Para a concretização das ações entre gestão do sistema e da escola básica, é necessário o atravessamento pela formação no ensino superior. Assim, quando se discute a efetivação de ações no que se refere à educação inclusiva, há, entre as políticas públicas e demais instâncias do sistema de ensino (gestão macro) e a concretização destas na escola de educação básica (gestão micro), um grande fator de influência: a formação de professores (instituição de gestão micro). Se a gestão das instituições de ensino superior não estiver em consonância com os princípios propostos pelo sistema educacional para a Educação Básica, não será possível êxito na qualidade da educação. Em harmonia, Lück (2006) aponta que, para a melhoria da qualidade da gestão educacional, é necessária ação ampla e continuada, envolvendo múltiplas dimensões articuladas entre si. Nesse sentido, pode-se afirmar que não são possíveis efetivas mudanças nas práticas de ensino universitário sem ações e mudanças na organização e gestão do curso (Libâneo, 2005).

Desse modo, não se pode deixar de mencionar aqui a ligação de tais aspectos com os documentos regulamentários que concretizam a ação pedagógica do curso. Internamente, como documento maior, considera-se o projeto político pedagógico, ou no caso do ensino superior, o projeto político pedagógico de curso. Os projetos devem estar de acordo com os princípios da formação que se deseja, tendo como base a gestão democrática de seus propósitos desde as instâncias maiores de políticas, regimentos, até seus coordenadores, professores e acadêmicos.

\section{Disciplinas sobre educação especial/educação inclusiva: currículo e projeto político-pedagógico como agentes de formação}

Tendo em vista a necessidade de planejamento apresentada por uma instituição de ensino, ou seja, de regulamento que concretizam a ação pedagógica do curso, a Universidade Federal de Santa Maria apresenta seu projeto político-pedagógico com o objetivo de definir princípios para orientação de suas atividades de ensino, pesquisa e extensão (UFSM, 2000). De acordo com o documento, "a existência de um projeto político-pedagógico de curso é importante para estabelecer referências de compreensão do presente, e de expectativas futuras." (2000, p.14). Desta forma, cada curso da instituição pode criar os seus próprios projetos político-pedagógico de acordo com seus princípios e fundamentos. Isso dá a possibilidade de cada curso da UFSM ter uma identidade clara, determinando suas prioridades e estabelecendo, com coerência, suas estratégias de trabalho (UFSM, 2000).

Entre os elementos que compõem o documento projeto político-pedagógico de curso, encontra-se o currículo, com sua estrutura, elenco de disciplinas, conteúdos etc. É a partir disso que se busca aqui articular as falas dos participantes com aspectos interligados a tais documentos, considerando questões propriamente curriculares.

Ao meio disso, é importante retomar algumas políticas públicas quanto à educação inclusiva e à formação de professores, pois se toma como base para reflexão a presença 
de disciplinas que abordem conhecimentos para subsidiar a prática pedagógica dos futuros professes. Assim sendo, há a resolução CNE/CP n. 1/2002 (Brasil, 2002), que estabelece as diretrizes curriculares nacionais para a formação de professores da educação básica, a qual alega no art. $6^{\circ}$ que, na construção do Projeto Pedagógico dos Cursos de formação dos docentes, devem ser considerados conhecimentos sobre as especificidades dos alunos incluídos. Destaca-se também o Plano Nacional de Educação (PNE) 2001-2010, que tinha como meta incluir, nos currículos de formação de professores, conteúdos e disciplinas específicas para a capacitação ao atendimento dos alunos especiais. Sobre a inclusão de Língua Brasileira de Sinais - Libras, o decreto n. 5.626, de 22 de dezembro de 2005, apresenta que a "Libras deve ser inserida como disciplina curricular obrigatória nos cursos de formação de professores", complementando a lei n. 10.436 (Brasil, 2002).

Logo, entre os oito participantes, seis afirmam existir na grade curricular dos cursos que coordenam disciplinas voltadas para o conhecimento sobre alunos com necessidades especiais, enquanto dois afirmam não existir. No entanto, apesar destes coordenadores confirmarem a inexistência de tais disciplinas, e de certa forma, falha na matriz curricular, percebe-se, em seus registros, o reconhecimento da necessidade de tais elementos, podendo ser tanto por motivos legais, políticos, quanto por seu próprio reconhecimento e entendimento sobre a necessidade. $\mathrm{Na}$ resposta do sujeito $\mathrm{B}$, verifica-se tal inferência. "Na sua matriz obrigatória não estão incluídas tais disciplinas. No entanto, sempre que possível eu procuro ofertar tais disciplinas como DCG". Percebe-se, na fala do gestor, certa preocupação com estes aspectos.

Em relação ao mesmo questionamento, a existência de disciplinas de Educação Especial/educação inclusiva, o sujeito A registra que: "Não. Esses temas são considerados transversais". Nesta fala percebe-se uma forma de justificar a não existência de algo mais concreto na estrutura do curso. No entanto, a fala trazida pelo sujeito $A$ é essencialmente relevante, pois tendo em vista que a Educação Especial, assim sendo a educação inclusiva, perpassa todas as etapas, modalidades e níveis, o professor deve ter em sua formação reflexões permanentes e transversais, pois sua atuação junto aos alunos incluídos não é isolada, e sim faz parte do todo.

Entre os respondentes que afirmam haver tais disciplinas nos currículos, a maioria relata a presença da disciplina Fundamentos da Educação Especial ou similar. Cinco coordenadores citam também a disciplina de Libras, informando que essas disciplinas foram implantadas entre os anos 2010 e 2011. Portanto, foram incluídas recentemente nos currículos, levando a crer que seja em virtude de estar de acordo com as legislações vigentes. Essa questão pode ser visualizada na fala do sujeito $G$ ao expor que "as disciplinas foram acrescentadas ao Currículo em atendimento a lei. Acredito que Fundamentos da Educação Especial, com 60h, tenha sido em 2004, quando houve reformulação do currículo. Em 2011 foi acrescentada a disciplina de Libras B, com 60h."

A partir da exposição, fica evidente a crescente inclusão da disciplina de Libras, o que remete à expansão da educação do surdo no país, principalmente no Ensino Superior, e particularmente, na UFSM.

Algumas disciplinas, apesar de serem relatadas como existentes no currículo do curso, não constam no projeto político-pedagógico do curso. Possivelmente, isso acontece por que elas foram inseridas recentemente nas estruturas curriculares, porém 
esse "recentemente" é relativo, pois, em dois anos, há tempo para a reformulação do projeto político-pedagógico do curso, o qual orienta a prática educativa expressando por tanto as exigências sociais e legais do sistema de ensino (Libâneo, 2004).

Nesse sentido, conforme o PPP da UFSM, "é necessária a articulação entre projetos políticos-pedagógicos e reformas curriculares, de modo que as orientações gerais do Curso estejam em coerência com os princípios de implementação do currículo." (UFSM, 2000). A partir disso, outras questões referentes aos projetos político-pedagógicos dos cursos são ressaltadas, entre as quais, destaca-se o fato que um curso, ao assumir uma formação de licenciados que considere a capacitação para a educação inclusiva, deve apresentar tais princípios no documento que regulamenta e dá o direcionamento de suas ações. Ou seja, apesar de existir na estrutura curricular dos projetos político-pedagógicos da maioria dos cursos algumas disciplinas sobre a Educação Especial, a grande maioria dos cursos de licenciatura da UFSM não traz nos objetivos dos projetos políticopedagógicos dos cursos, a formação para atender a demanda da inclusão.

Analisando os projetos político-pedagógicos dos cursos de licenciatura, constata-se que, entre os dezenove cursos estudados, apenas três apresentam claramente, nos objetivos dos seus projetos político-pedagógicos, a necessidade de formação para a educação inclusiva. O primeiro é o curso de Música que apresenta, entre os objetivos específicos, compreender o trabalho com alunos com necessidade especiais.

O segundo é o curso de Pedagogia Licenciatura Plena - diurno que, igualmente ao de Música, apresenta, em seus objetivos específicos, a compreensão sobre a política de inclusão. Neste mesmo curso, outros objetivos específicos abrem a possibilidade de discussão sobre os princípios da educação inclusiva.

Por fim, o terceiro é o Curso de Pedagogia Licenciatura Plena - Noturno. Nele, em um dos objetivos específicos, há a busca de solução para problemas da realidade, ou seja, a educação inclusiva é incluída nessa preocupação. Ainda, pode-se perceber que o curso apresenta o seu objetivo geral mais abrangente, abre a possibilidade para uma formação que forme para atuar nas diferentes modalidades de ensino.

Em face às problematizações acima expostas, compreende-se que a instituição de Ensino Superior, em especial na UFSM, está em processo de construção de ações que contemplem e que realmente considere, para a formação inicial de professores, a educação inclusiva. Sendo assim, percebe-se certo avanço, porém não se pode deixar de mencionar que muito ainda deve ser feito. As mudanças estão ocorrendo gradualmente, pois, como já disse Veiga (2003), "a introdução do novo implica mudança do todo pela mudança das partes" (p. 269), ou seja, algumas pequenas mudanças estão sendo desenvolvidas para que outras maiores sejam percebidas como necessárias. No entanto, "as inovações não têm hipóteses de sucesso se os atores não são chamados a aceitar essas inovações e não se envolvem na sua própria construção" (Benavente, 1992 apud Veiga 2003, p. 269).

Logo, somente com a ação conjunta dos coordenadores e todos os atores que fazem a instituição ser concretizada, acreditando nas necessidades de mudanças, ter-seá êxito e garantia de uma formação docente de qualidade que reflita em formação básica de qualidade.

Ainda, através da análise dos princípios e os objetivos apresentados nos projeto político-pedagógicos dos cursos de licenciatura, mais uma problemática não pode deixar 
de ser mencionada, ou seja, alguns cursos de licenciatura estão voltados à formação específica, sem abranger as questões pedagógicas e propriamente da docência, formando, assim, verdadeiros bacharéis, ao invés de professores propriamente ditos. Essa estrutura parece não contribuir para a identidade da profissão de professor, e pouco se abre a possibilidade de reflexão e formação para a educação inclusiva.

\section{Ações desenvolvidas nos cursos de licenciatura: buscando formação para atuar na escola inclusiva}

Ao serem questionados sobre a existência de ações que identifiquem as necessidades de formação dos acadêmicos, os coordenadores relatam, em sua grande maioria, que não há esse espaço. Essa constatação leva a pensar sobre a forma de gestão desenvolvida pelos cursos, considerando os princípios de uma gestão realmente democrática que atenda a participação de todos, pode-se constatar que ainda não se encontra esta realidade, pois o aluno - como sujeito que faz a universidade existir - deve participar do processo de construção das ações as quais envolvem as melhorias de seus cursos.

Nesse sentido, no PPP da instituição (UFSM 2000), encontra-se que "cada aluno deve ser encarado pela instituição como um sujeito capaz de participação atuante no âmbito coletivo, de entendimento do contexto em que vive, e de avaliação ética dos problemas colocados pela realidade" (p. 22-23). Em relação à educação inclusiva, através de pesquisa anterior ${ }^{5}$, os acadêmicos mencionam a necessidade de melhoria, citando diversos problemas e lacunas na organização de seus cursos que acreditam ser pensadas e aprimoradas para suas formações.

Assim, há uma percepção de que não há espaços para essas questões e opiniões dos alunos cheguem até a gestão do curso. Ou seja, não há uma interconexão entre as partes envolvidas pela concretização e desenvolvimento da instituição.

A oportunidade de participação, através de espaços para que os alunos possam pronunciar suas inquietações e sugestões, nesse entendimento, deveria ser considerado como princípio norteador, o que parece estar ocorrendo lacunas nesse processo. No entanto, dois dos coordenadores respondentes citam algumas formas de possibilidade de espaço para ouvir as imposições dos alunos nos seus cursos.

Para exemplificar, o sujeito $\mathrm{H}$ responde que "os acadêmicos mantêm discussões durante todo o curso sobre inclusão/exclusão. Periodicamente, por ocasião das avaliações do pedagógico do curso, apresentam demandas quanto a este e outros temas de interesse."

Neste caso é apontada a existência de espaço para discussão e reflexão dos alunos juntamente com os professores. Porém, caso não haja a interconexão entre os atores, alunos - professores - coordenação e demais instâncias da gestão, a ação não terá sucesso. Outro momento importante citado pelo participante são as avaliações do curso, a existência deste momento deveria estar presente em todos os cursos. Assim, embora existam, nas falam dos sujeitos, possibilidades de discussões, não há necessariamente de mudanças efetivas.

${ }^{5}$ Machado, 2010. 
Sobre as alternativas que a coordenação do curso desenvolve para contribuir com conhecimentos para a educação inclusiva, constata-se que, entre os oito participantes, apenas três citam não haver no curso alternativas, além das disciplinas, para contribuir na formação para a educação inclusiva. A grande maioria aponta algumas formas e alternativas que a gestão do curso desenvolve com o intuito de complementar a formação dos futuros professores. Desse modo, foram identificados três grupos de respostas referindo-se às alternativas existentes. Elas são: atividades extracurriculares; apelo a órgão consultivo e propositivo; e Disciplinas Complementares de Graduação-DCGs.

Em relação ao primeiro grupo de respostas, encontra-se a existência de atividades como palestras, oficinas, grupos de estudos. No registro do participante $\mathrm{H}$, há: "Nos eventos organizados pelo Curso são ofertadas palestras, oficinas ou outras atividades sobre o tema. Sempre que nos visitam pesquisadores sobre o tema, aproveitamos sua estadia na UFSM, para palestras."

Já o participante A diz que "sempre que for necessário ou surgirem demandas a coordenação deve apoiar iniciativa e também promover situações de realização de atividades, tais como grupo de estudo, palestras, eventos."

A segunda resposta responde ao aspecto de quais as alternativas são desenvolvidas, porém pode-se perceber que, na fala, é destacado o papel da coordenação abrindo espaço para pensar que não é o que acontece, mas sim o que deveria acontecer. Em relação às duas respostas, pode-se destacar que, apesar da aproximação do rumo das alternativas existentes, há uma grande diferença de princípios e crenças. Enquanto, na primeira, o sujeito $\mathrm{H}$ parece acreditar na necessidade de discussões, ter como algo permanente e inquestionável, o sujeito $\mathrm{A}$ parece não acreditar nesta necessidade, sendo preciso a demanda, o "pedido" direto à coordenação, ou seja, demonstra que por si só, como gestor e professor, não vê tais alternativas como uma demanda ao curso.

O segundo grupo de respostas incorporado para análise diz respeito às possibilidades reivindicadas à instância maior no âmbito dos cursos. Dois dos participantes citam o Núcleo Docente Estruturante (NDE) como órgão competente que poderia analisa a possibilidades de alternativas. $O$ participante $B$ responde à questão da seguinte forma: "Estamos solicitando ao Núcleo Docente Estruturante (NDE) que considere tal possibilidade, visto que o licenciado precisa estar preparado para atuar numa sala de aula inclusiva."

No discurso, há a consideração de que a partida inicial foi tomada, que está buscando melhorias para o curso. Além disso, parece evidente o seu posicionamento, acreditando na necessidade dos docentes em formação estarem mais bem preparados para a educação inclusiva. Cabe destacar que o NDE é um órgão consultivo e propositivo em matéria acadêmica, responsável pela concepção, acompanhamento, consolidação e avaliação do respectivo projeto pedagógico dos cursos de graduação (UFSM, 2011).

Passando para o terceiro grupo de respostas, encontra-se como forma de buscar alternativas, além das disciplinas da grade curricular, a oferta de disciplinas complementares de graduação: "Há também discussões sobre inclusão em DCGs" (sujeito C). Esta alternativa mostra-se como a mais concreta e fácil de ser desenvolvida pelas coordenações dos cursos, até mesmo aos cursos que ainda não têm disciplinas sobre a temática, como elucidado anteriormente. 
O terceiro e último eixo de análise desta categoria diz respeito a oportunidades que os coordenadores acreditam que os alunos tenham para buscar subsídios e conhecimentos para atuar na educação inclusiva. Desta forma, entre os participantes, três apenas acreditam não existir outras formas para os alunos buscarem conhecimento. Entre os que acreditam haver tais formas, encontram-se, principalmente, as disciplinas, assim como atividades extracurriculares como palestras, cursos etc. O participante A descreve que os alunos podem buscar conhecimento, "através das disciplinas formativas docentes". Estas referem-se às de formação pedagógica, como Psicologia da Educação, Políticas Públicas e Gestão na Educação Básica, Didáticas, entre outras.

$\mathrm{Na}$ fala do colaborador da pesquisa $\mathrm{D}$, encontra-se uma problemática muito pertinente. O gestor afirma que "alternativas que, de fato, gerem um ganho ao discente no quesito conhecimento/experiência no âmbito da inclusão em educação dependem, primordialmente, de um corpo docente que possua tais condições."

Acredita-se que a afirmação acima é o eixo a ser problematizado quando se discuti a formação de qualidade dos professores para receber o aluno incluído. O professor formador, considerando as políticas educacionais atuais, deve estar preparado para trabalhar com a formação que traga esta demanda.

\section{Formação do professor de educação básica em tempos de inclusão educacional: questões, transformações e avanços}

Através dos significados e atribuições desvelados, detém-se aqui a analisar as questões relacionadas à avaliação da proposta do curso na concepção dos coordenadores, além dos problemas enfrentados e das mudanças necessárias. Nesse sentido, tal ação faz-se necessário ao considerar que

como instituição que cultiva o trabalho da razão e da formação humana, a universidade se institui e se autojustifica a medida que faz a crítica de si mesma, da sociedade, da cultura, da existência humana, dos saberes, das ideias, dos conceitos, das teorias, dos métodos e da prática. (Coêlho, 2005, p. 55).

É justamente através dessa avaliação crítica, proposta aqui, por meio dos coordenadores, que a instituição poderá alcançar níveis elevados de qualidade, além de estar constituindo-se como universidade logo que busca respostas aos desafios da sociedade. Dessa forma, ao propor aos coordenados dos cursos de licenciatura da UFSM que avaliem a proposta atual dos seus cursos no que se refere à formação para atuar na educação inclusiva, a maior parte dos participantes responde negativamente, acreditando ser deficitária ou insuficiente.

Alguns posicionamentos tornam-se indispensáveis de serem refletidos, principalmente como forma da instituição repensar ações e propor espaço para debates e reformas estruturais, organizativas e principalmente formativas. Entre eles, encontra-se uma problematização frente às significâncias dada à inclusão dentro de seu curso. "Vejo que a proposta atual do curso não coloca a inclusão num patamar elevado, especialmente quanto ao tempo em sala de aula destinado a isso" (sujeito D).

Esta afirmação revela que, em muitos momentos, esse tema é deixado de lado, ou até mesmo assumindo apenas como forma burocrática de seguir as legislações. Essa 
situação não contribui com o objetivo central de entendimento sobre o tema, muito menos com uma formação de qualidade, pois a posição assumida pela instituição, e sua gestão, reflete na construção de ideias do aluno. Logo, deve-se ter claro que não é com a obrigação que se construirá ações positivas frente à inclusão, mas sim acreditando e querendo fazer parte desse processo (Beyer, 2006).

O mesmo participante complementa a reflexão anterior trazendo um contraponto ao fato de se pensar apenas em disciplinas, como forma de ampliar os conhecimentos dos acadêmicos. Em seu registro aponta que

obviamente, o trabalho com qualquer tema não depende da presença deste em forma de "disciplina", pois há inúmeros projetos e pesquisas nas quais nossos alunos podem engajar-se; estas iniciativas ocorrem atualmente, mas dependem prioritariamente do aluno de graduação.

Como já apontado pelo participante, depende do aluno ter interesse e buscar a inserção nesses grupos. Nem sempre o aluno tem autonomia para tanto, além do mais é bem provável que nem todos tenham interesse; no entanto, em suas práticas docentes, não poderão fazer essa escolha, e os sujeitos que lá estarão incluídos dependerão de um bom trabalho deste profissional, o professor. Outra problemática decorrente ao que propõe o participante acima está no fato que não há um número suficiente de projetos para contemplar todos os interessados, visto que esses são mais concentrados em alguns centros de ensino, além do mais, a maioria é voltada para áreas específicas. Logo, apesar da iniciativa ser muito relevante para o aprimoramento do conhecimento do acadêmico e principalmente para abrir novas possibilidades de reflexão e de busca de novos estudos, não deve ser a única oportunidade ou forma para que os alunos busquem melhores condições para o trabalho.

Por fim, apenas dois coordenadores, ao avaliarem a proposta do curso, trazem respostas positivas. Um deles acredita que a proposta do curso é "bem implementada, mas pouco crítica". O participante refere-se às disciplinas que são oferecidas (Educação Especial: Fundamento e Libras). O posicionamento, ao acreditar ser "pouco crítica", levanta a ideia de que disciplinas como essas não trazem contribuições ao curso e a consecutiva formação dos futuros professores.

Nesse sentido, outro participante, ao explanar sobre problemas de ordem organizativa e de gestão que poderia haver no curso, traz novamente a questão das disciplinas, apoiando a ideia de que poucas disciplinas não fariam a diferença, acreditando que o necessário para o trabalho na educação inclusiva é a formação continuada. Em suas palavras,

os problemas para a formação de professores qualificados para atuar na inclusão ultrapassam as questões de gestão, gerenciamento e currículos. Há necessidade de apoio e ações na formação continuada dos professores. Não será uma ou duas disciplinas na graduação que dará preparo e qualificação para os professores. (Participante A)

De certa forma, aqui novamente parece ser transmitida a responsabilidade através de uma justificativa. No entanto, a formação continuada é prática indispensável da vida do professor, principalmente ao abordar o tema da educação inclusiva, viso que cada sujeito 
é único, cada necessidade especial é única. A profissão do professor exige que sempre esteja atualizado com seu tempo e contexto socio-histórico. Em vista disso, lembra-se que "as fontes de formação profissional dos professores não se limitam à formação inicial na universidade; trata-se, no verdadeiro sentido do termo, de uma formação contínua e continuada que abrange toda a carreira docente" (Tardif, 2002, p. 287).

Todavia, a formação inicial não deixa de ter sua responsabilidade, pois se acredita ser o período que se constrói as bases e fundamentos do ser professor, do ensino e, especialmente, das principais bases e fundamentos que regem a educação inclusiva e os sujeitos dela beneficiados. Sendo assim, compartilha-se da ideia apontada por Tardif (2002), ao afirmar que "a formação inicial visa a habituar os alunos - os futuros professores - à prática profissional dos professores de profissão e a fazer deles práticos reflexivos" (p. 288).

Parte-se, agora, para um dos principais problemas apontados pelos coordenadores, o despreparo do corpo docente da instituição. Nesse sentido, em diferentes questões propostas aos participantes, encontra-se, como resposta, a falta de preparo dos próprios professores formadores de professor. Nas indagações sobre a proposta do curso no que se refere à educação inclusiva, como também quanto aos problemas e às mudanças que acreditam existir, encontra-se essa problemática.

$O$ participante $D$, quando indagado sobre os problemas relacionados, a gestão responde que "a qualificação profissional dos professores em formação poderia contemplar o preparo para o trabalho com uma educação inclusiva, mas o corpo docente, neste aspecto, possui mais peso do que a coordenação ou a administração central da universidade".

Com a fala anterior, é possível acreditar que exista uma falha nesse aspecto, levando a pensar que os maiores problemas não estão na gestão, mas na falta de preparo do corpo docente. Desta forma, questiona-se se tal problema não envolveria a gestão dos cursos, e principalmente, a gestão central? Se há uma lacuna entorno do corpo docente, o que precisa ser feito para melhorar?

Corroborando com a reflexão frente à problemática apontada, não se pode omitir algumas falas que desapontam as percepções e expectativas em torno da temática estudada, como esta: "Não tenho condições de responder, pois não conheço a área" Isso leva a uma reflexão quanto ao despreparo dos professores formadores e dos gestores no âmbito dos cursos de licenciatura. A reflexão parte do questionamento que busca avaliar a proposta do curso frente à educação inclusiva. Poderia um profissional da educação, docente formador e gestor não conhecer a área? Ou melhor, não conhecer os aspectos que constroem o próprio curso ao qual coordena?

Muitos são os questionamentos e as preocupações, pois se não há profissionais engajados, responsáveis e conhecedores dos princípios educacionais, não se alcançará qualidade na formação e, consequentemente, na Educação Básica. Como resposta ao questionamento sobre os problemas do curso em relação a educação inclusiva, o sujeito $B$ responde da seguinte forma: "Não posso avaliar a gestão, pois desconheço a literatura especializada". Isso mostra o despreparo do professor gestor, além da inferência de que desconhece nas legislações que cabem ao Ensino Superior, ou melhor, aos cursos de licenciatura. Em instância maior, assume claramente não ser conhecedor das políticas atuais da educação básica, visto que, como professor e formador de outros professores, 
teria o dever de situar-se dentro do contexto social-político-educacional em que a educação brasileira encontra-se.

Nesse contexto, é pertinente a colocação do participante $\mathrm{H}$, ao descrever sobre os problemas que podem ser encontrados na organização do curso:

Cada escola apresenta limites e possibilidades na área. Entendo que estejamos aprendendo a produzir uma efetiva educação inclusiva. Por isso, são naturais os movimentos de resistência, desconhecimentos. Entretanto, embora naturais, devem ser superados e, para tanto exige estudos em contínuo.

Nesse sentido, a fala do participante acima resume tudo, ou pelo menos quase tudo que é necessário no ensino superior. Ou seja, muito estudo ainda carece, tanto dos formadores quanto dos formandos. Em relação à educação inclusiva, particularmente à formação para uma educação inclusiva de qualidade, não há ação perfeita, nem é o intuito, porém a universidade está em processo, "aprendendo a produzir" ações que representam progressivamente tal qualidade. No entanto, ainda existe a resistência e, principalmente, o desconhecimento, mostrando que muitas mudanças e aprimoramentos são imprescindíveis. É pelo convencimento gradual e pelo reconhecimento das principais bases do projeto de inclusão que os professores tornar-se-ão como parte e, assim, resultados positivos (Beyer, 2006). Logo, pode-se considerar que

o sucesso de qualquer reforma depende do envolvimento activo dos professores no seu desenvolvimento e concretização. Se os professores não participarem activamente e não sentirem que a reforma também lhes pertence é praticamente impossível que qualquer mudança venha a ter sucesso. (Novoa, 2007, p. 8)

Desse modo, muitas inquietações ainda ficam, com a certeza de que há muito o que melhorar, reformas urgentes dever ser realizadas, assim como concepções e sentidos atribuídos devem ser constantemente refletidos, repensados, reavaliados. No entanto, "O processo educacional só se transforma e se torna mais competente na medida em que seus participantes tenham consciência de que são co-responsáveis pelo seu desenvolvimento e seus resultados" (Lück, 2006, p. 76).

\section{Considerações finais}

A educação inclusiva não é tema recente de estudos, muito já foi e está sendo estudada, pesquisada e discutida. No entanto, apesar do tratamento dado a esse tema, ele não se esgota, pois há muito ainda que investigar, debater, repensar, analisar. Em relação ao tema formação para educação inclusiva, há muitas reflexões, principalmente por que isso tem sido encarado como o principal problema quanto à educação dos sujeitos com necessidades educacionais em sala regular de ensino. Do mesmo modo, pensar em alternativas que busquem suprir essa lacuna é essencial para uma formação de professores de qualidade.

Discutir a existência da política de educação inclusiva aqui não foi o intuito, mas sim se buscou formas de pensar, existindo uma política de inclusão educacional, ainda que com suas falhas e incertezas, e o que o ensino superior pode fazer para que a inclusão 
seja assumida e realizada de forma coerente, diminuindo as dificuldades e desafios que se encontram para uma educação básica de qualidade.

A partir dos princípios da gestão democrática, acredita-se que significativas mudanças e ações nos cursos de licenciaturas não dependem exclusivamente de seus coordenadores, mas sim do envolvimento de todas as instâncias e atuantes no sistema superior de ensino, ou seja, desde as pró-reitorias, passando por colegiados de curso, núcleos docentes estruturantes, até os professores, principais atores e concretizadores da formação docente e seus alunos.

Não se pode deixar de considerar os problemas enfrentados, por uma política que preconiza a educação inclusiva, que foi imposta sem muito preparo e entendimento dos principais concretizadores da educação, seus professores. No entanto, as lacunas também podem ser apontadas na formação docente, pois a implementação de políticas públicas deveria ser uma construção conjunta com trabalho cooperativo e principalmente com o conhecimento e o preparo prévio dos seus atores.

Uma seguinte questão que surge é em relação à formação inicial e formação continuada. Percebendo a falta de incentivos na formação inicial para os estudos da área em questão, fica o questionamento se a formação vai ficar a cargo apenas dos estudos continuados, após o aluno já estar na sala de aula. Sabe-se que a formação continuada é fundamental na profissão dos professores, e claro, principalmente quando se refere ao aluno com necessidades educacionais especiais. Porém, hoje a educação inclusiva é um principio básico da educação em todos os níveis, de tal modo que a formação do professor não pode vir somente após sua atuação, mas sim sair de seu curso conhecedor dos princípios que regem a educação inclusiva.

Mais um ponto interessante de ser levantado, a partir do estudo realizado, é a diferença entre alguns cursos de licenciatura da UFSM. Alguns cursos evidenciaram maior preocupação nas áreas específicas de seus cursos, e não demonstrando preocupações pedagógicas, sendo a maioria aqueles cursos que formam profissionais que atuarão no ensino médio ou nas séries finais do ensino fundamental. $O$ fato de haver mais ações, através de disciplinas pedagógicas, principalmente nos cursos que formam para atuação em anos iniciais, contempla uma relação, ou seja, ao considerar a evolução histórica, além da inclusão educacional ser algo relativamente novo, há mais mobilização e efetivação de inclusão no ensino fundamental, principalmente nos anos iniciais. Já em relação aos anos finais e ao ensino médio é recente o crescimento de inclusão educacional, como também no ensino superior.

Um dos principais problemas evidenciados na pesquisa foi a falta de preparo do corpo docente formador de professores para trabalhar com a educação inclusiva. Se os professores e gestores não tiverem conhecimento sobre isso não estão preparados para a atualidade, como formarão professores para tal? Além disso, como serão construídos espaços que contemplem a formação dos docentes se nem mesmo os seus gestores e professores já adentraram nas questões que tocam o tema? Sendo assim, muitos outros questionamentos permanecem, sobretudo frente à formação continuada dos docentes formadores e dos gestores no âmbito da educação inclusiva. 


\section{Referências}

BARDIN, Laurence. Análise de conteúdo. Lisboa: Edições 70, 1977.

BEYER, Hugo Otto. Da integração escolar à educação inclusiva: implicações pedagógicas. In: BAPTISTA, C. R (org.). Inclusão e escolarização: múltiplas perspectivas. Porto Alegre: Mediação, 2006, p. 73-81.

BRASIL. Diretrizes curriculares nacionais para a formação de professores da educação básica, em nível superior, curso de licenciatura, de graduação plena. Resolução CNE/CP n. 1, de 18 de Fevereiro de 2002.

BRASIL. Constituição da República Federativa do Brasil. Brasília: Imprensa Oficial, 1988.

BRASIL. Decreto n. 5.626, de 22 de dezembro de 2005.

BRASIL. Política nacional de educação especial na perspectiva da educação inclusiva. MEC/SEESP, Brasília, 2008.

BRASIL. Plano Nacional de Educação. Lei n. 10.172, de 9 de janeiro de 2001. Disponível em <http://www.planalto.gov.br/ccivil 03/leis/leis 2001//10172.htm>. Aceso em: 27 out. 2010.

BRASIL. Lei de Diretrizes e Bases da Educação Nacional. LDB 9.394, de 20 de dezembro de 1996.

COÊLHO, Ildeu Moreira. A universidade, o saber e o ensino em questão. In: VEIGA, Ilma Passos Alencastro; NAVES, Maria Lomônaco de Paula. Currículo e avaliação na educação superior. Araraquara: Junquiera \& Marin, 2005, p. 53-77.

GIL, Antonio Carlos. Métodos e técnicas de pesquisa social. São Paulo: Atlas, 1999.

JESUS, Denise Meyrelles de. Integração escolar, formação continuada e pesquisa-ação colaborativa. In: BAPTISTA, C. R. (org.). Inclusão e escolarização: múltiplas perspectivas. Porto Alegre: Mediação, 2006, p. 95-106.

LIBÂNEO, José Carlos. Adeus professor, adeus professora?: novas exigências educacionais e profissão docente. São Paulo: Cortez, 2006.

LIBÂNEO, José Carlos; OLIVEIRA, João Fereira; TOSCHI, Mirza Seabra. Educação escolar: políticas estrutura e organização. São Paulo: Cortez, 2005.

LIBÂNEO, José Carlos. Organização e gestão da escola: teoria e prática. Goiânia: Alternativa, 2004.

LÜCK, Heloisa. Gestão educacional: uma questão paradigmática. Petrópolis: Vozes, 2006.

MACHADO, Charline Fillipin. Formação docente para a educação inclusiva: a necessidade de reconhecimento dos alunos com altas habilidades/superdotação. Santa Maria: UFSM, 2010. Monografia (trabalho de conclusão de curso). Centro de Educação, Universidade Federal de Santa Maria.

MINAYO, Maria Cecília de Souza (org.). Pesquisa social: teoria, método e criatividade. Petrópolis: Vozes, 2011.

NOVOA, Antônio. O regresso dos professores. Conferência: Desenvolvimento profissional de professores para a qualidade e para a equidade da aprendizagem ao longo da Vida. Presidência Portuguesa do Conselho da União Europeia. Lisboa: Ministério da Educação, 2007. Disponível em: <http://escoladosargacal.files.wordpress.com/2009/05/regressodos professoresantonionovoa.pdf>. Aceso em: 28 nov. 2012. 
TARDIF, Maurice. Saberes docentes e formação profissional. Petrópolis: Vozes, 2002.

UFSM. Projeto político-pedagógico. Santa Maria: UFSM-Pró-Reitoria de Graduação, 2000.

UFSM. RESOLUÇÃO N. 14/11. Institui o Núcleo Docente Estruturante - NDE - no âmbito dos cursos de graduação da Universidade Federal de Santa Maria e estabelece suas normas de funcionamento. 2011.

VEIGA, IIma Passos. Inovações e projeto político-pedagógico: uma relação regulatória ou emancipatória? Cad. Cedes. Campinas: v. 23, n. 61, 2003, p. 267-281.

Charline Fillipin Machado é professora de educação especial em Júlio de Castilhos, RS.

Endereço: Rua Jão Attilio Zampiere, 132/102 - 97105-490 - Santa Maria RS - Brasil.

E-mail: charlinefm@hotmail.com.

Fabiane Adela Tonetto Costas é professora no Centro de Educação da UFSM.

Endereço: Avenida Roraima, 1000 - prédio 16 - 97119-900 - Santa Maria RS - Brasil.

E-mail: fabicostas@gmail.com.

Recebido em 25 de julho de 2013.

Aceito em 19 de agosto de 2013. 